\author{
Imzahim A. Alwan \\ Civil Engineering \\ Department, University of \\ Technology, Baghdad, Iraq \\ 40164@uotechnology.edu.iq
}

\section{H. H. Karim}

Civil Engineering

Department, University of

Technology, Baghdad, Iraq.

\section{Nadia A. Aziz}

Ministry of Science and Technology, Directorate of Space and Communication Baghdad, Iraq.

Received on: 11/07/2018

Accepted on: 10/01/2019

Published online: 25/05/2019

\section{Selecting the Potential Water Harvesting Sites Using Fuzzy GIS-Based Spatial Multi-Criteria Evaluation in Salah Al-Din Governorate, Iraq}

Abstract- Remote sensing and GIS-based techniques were used to select the potential sites for water harvesting in Salah Al-Din Governorate, northern Baghdad/Iraq. Spatial Multi-Criteria Evaluation (MCE) was used where seven criteria layers have been evaluated to identify water-harvesting sites, such as slope, stream order, precipitation, potential evaporation rate, soil type, distance to roads and the Normalized Difference Vegetation Index (NDVI). This method helps in locating water-harvesting sites in suitable places as well as improves the management of water resources in the study area. Fuzzy logic modeling was used to standardize the criteria layers, and the Fuzzy Gamma overlay was used to combine these layers together in ArcGIS 10.5. Specific criteria were used to unify all these layers. Finally, the final suitability map for the potential water harvesting sites in Salah Al-Din area was produced were twelve potential waterharvesting sites within the study area have been identified according to the specific criteria used for this purpose and have a high potential for water harvesting. This map will provide optimum sites to build dams in order to store the water, especially in drought-stricken areas. The results illustrate that the GIS can be used as a decision-making tool in water resources management in a scientific approach, which makes the decision making easier and accurate.

Keywords- Fuzzy Logic, GIS Models, MCE, Remote Sensing, Water-harvesting.

How to cite this article: I.A. Alwan, H.H. Karim and N.A. Aziz, "Selecting the Potential Water Harvesting Sites Using Fuzzy GIS-Based Spatial Multi-Criteria Evaluation in Salah Al-Din Governorate, Iraq," Engineering and Technology Journal, Vol. 37, Part C, No. 2, pp. 219226,2019

\section{Introduction}

Water is a crucial need for a human in many aspects of living, such as domestic, industrial, municipal, agriculture, etc. However, its availability for those particular needs is depleted due to changes in environmental condition pertaining to water and to some extent to the increase of water requirement. The waterharvesting process can be defined as collecting the water from the catchments area for useful usage. Water-harvesting method enhances agricultural productivity through leading the rainwater during run-off to the plants. The water harvesting approach offers significant potential for sustaining agricultural production spatially in the semi-arid region.

Arid and semi-arid areas are frequently facing water scarcity problems for domestic use and agriculture. The arid and semi-arid area represents $35 \%$ of Earth's land, about 50 million $\mathrm{km}^{2}$ [1]. The water-harvesting method should be adopted essentially in arid and semi-arid areas, to treat the drought problem and the climate change conditions effectively.

Integrated remote sensing (RS) data and geographical information system (GIS) can consider being an effective tool to identify the potential water harvesting sites. Generally, the multi-criteria decision problems include a set of a potential decision alternative that is evaluated based on specific criteria. GIS-based multicriteria decision analysis is a process that integrates the spatial data to get an overall assessment of the decision alternatives [2]. GISbased-MCE methods are the most effective method for the site suitability analysis. GIS technique is used to construct the site suitability model by formulating different criteria maps [3]. Over the last decade, a number of MCE studies have been performing in the GIS environment for various purposes with good results, such as Malczewski [4]; Srivastava, et al. [5]; Chen et al. [6]; Rikalovic et al. [7]; Adham et al. [8]; Aziz et al. [9].

This study aimed to select the potential sites for water harvesting in Salah Al-Din Governorate, North Iraq utilizing remote sensing and GISbased Spatial Multi-Criteria Evaluation (MCE). Fuzzy logic modeling was used to standardize the layers and combined the criteria layers together in ArcGIS 10.5. This research is important because it relates to several areas such as water

DOI: https://doi.org/10.30684/etj.37.2C.4

2412-0758/University of Technology-Iraq, Baghdad, Iraq

This is an open access article under the CC BY 4.0 license http://creativecommons.org/licenses/by/4.0 
management, agricultural productivity, sustainable environment, and human livelihoods.

\section{Materials and Methods}

\section{Study Area}

The study area lies in Salah Al-Din Governorate north of Baghdad capital, which located between longitudes $42^{\circ} 00^{\prime}-45^{\circ} 05^{\prime} \mathrm{E}$, and latitudes $33^{\circ}$ $00^{\prime}-36^{\circ} 00^{\prime} \mathrm{N}$ (Figure 1). Topographically, it is semi-flat with the presence of some elevated local features represented by the deposits of river terraces and several depressions [10]. Geologically, most of the area is covered by Quaternary deposits (Pleistocene) included the alternation of sediments, sand, gravel, clay which belongs to recent sediments. Pre-quaternary deposits belong to Tertiary, which represented by Mukdadiyah Formation (Pliocene) which consist the alternation of sandstones, siltstones, claystones, and Injana Formation (U. Miocene) a sequence of silty, sandy, gravel and mud, suitable for groundwater storage. Tectonically, the area lies in the Stable and Unstable Shelf geotectonic units within the Mesopotamian zone, AmmaraTikrit secondary subzone [11]. The study area is an important economic area, where the population is working in agriculture, especially crops of grain production, such as wheat, barley, corn, farmers depend on rainwater and groundwater as water to plant some summer and winter vegetables. The areas of the two banks of the Tigris and the Al-Idhaim_rivers depend on the water of these rivers for agriculture.

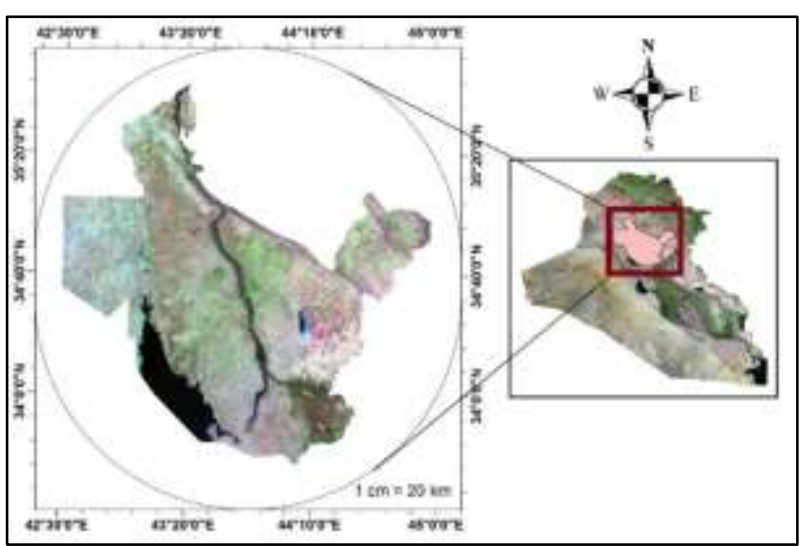

Figure 1: Location of the study area

\section{Dataset}

The various dataset was used in this study; ArcGIS version 10.5 was utilized to analyze these data. The Universal Transverse Mercator (UTM) system, WGS 84 and zone $38 \mathrm{~N}$ was used to georeference all the thematic-layers.

\section{a. DEM}

The NASA SRTM obtained elevation data using radar interferometry with a spatial resolution 1 Arc Sec $(30 \mathrm{~m})$, this product was released on Jan 2015 by the LP DAAC. The STRM V.3 is voidfilled using elevation data from ASTER GDEM2, USGS GMTED 2010, and USGS National Elevation Dataset [12]. In this study, STRM V.3 DEM was used to drive the order of the stream using the hydrology tools in ArcGIS 10.5 (Figure 2 ), in addition, to drive the slope map (Figure 3).

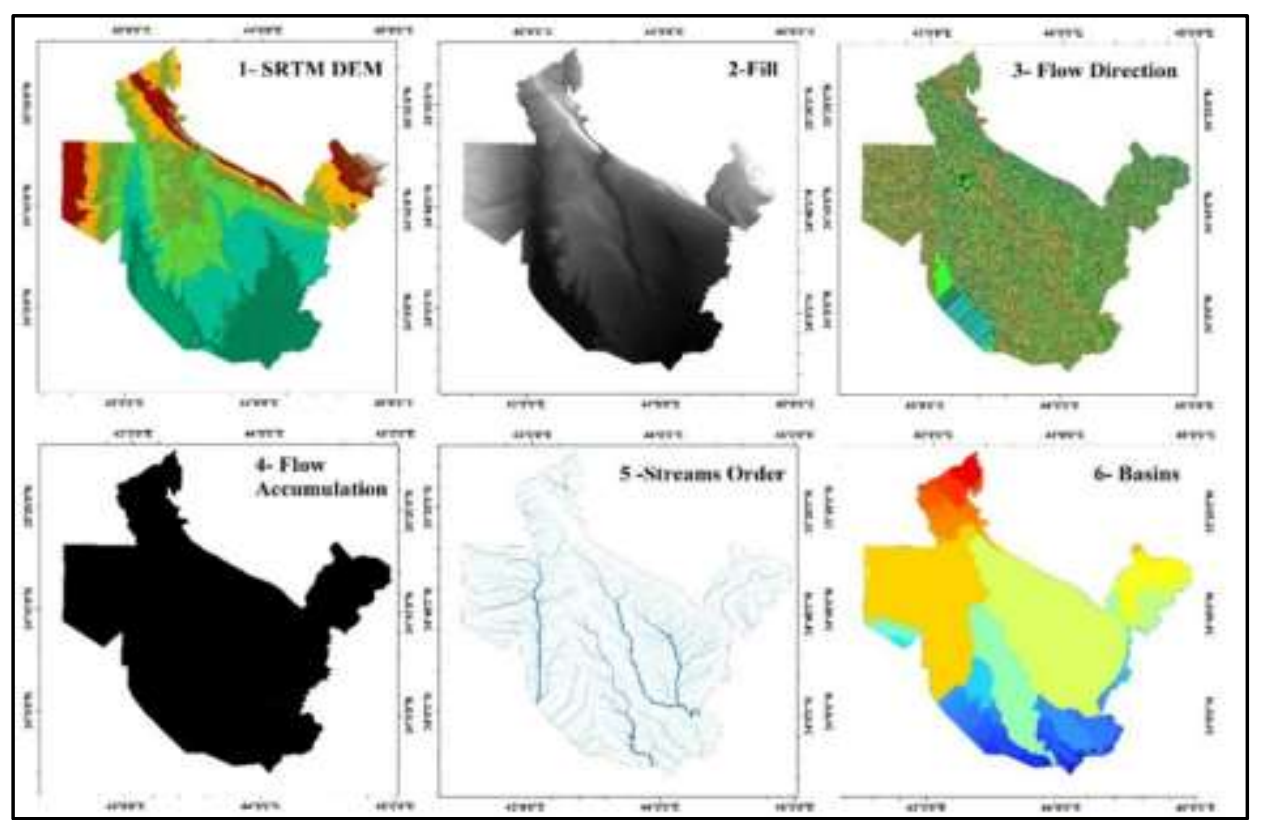

Figure 2: DEM processing steps to derive the order of the stream 


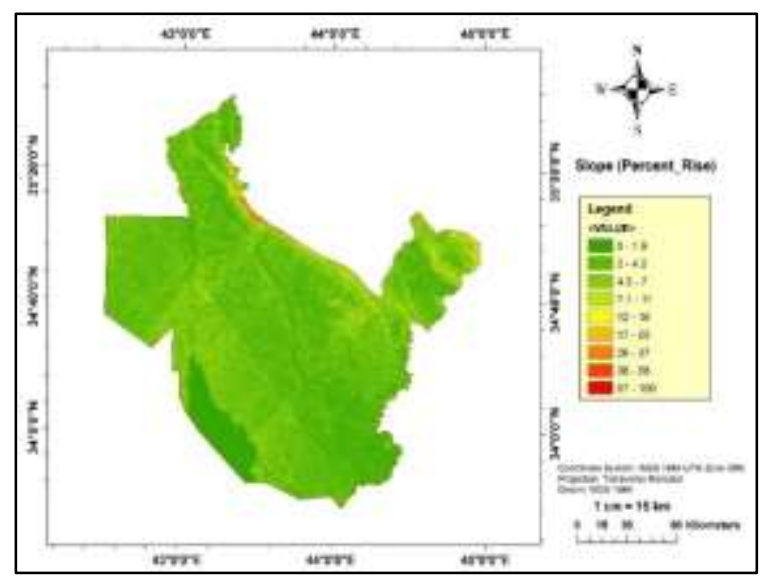

Figure 3: Slope map

b. Satellite-based climate data

Remote sensing rainfall estimation from the Tropical Rainfall Measuring Mission (TRMM) is a potential way of supplementing the rain gauge data with a good spatial distribution [13]. Climate data for the period $2000-2018$ based on satellite data were downloaded and processed with spatial resolution 0.25 deg. Time-averaged map of precipitation rate monthly per $\mathrm{mm} /$ month is shown in Figure 4.

The Global Land Data Assimilation System (GLDAS) aims to integrate the satellite-based data and ground observational data, by advanced land surface modeling and data assimilation techniques, to generate optimal fields of land surface states and fluxes [14]. The potential evaporation monthly rate was downloaded from GLDAS Model_NOAH025 in $\mathrm{W} / \mathrm{m}^{2}$ for the period 2000 Jan - 2018 Jan. Time-averaged map of potential evaporation rate monthly 0.25 degree is shown in Figure 5.

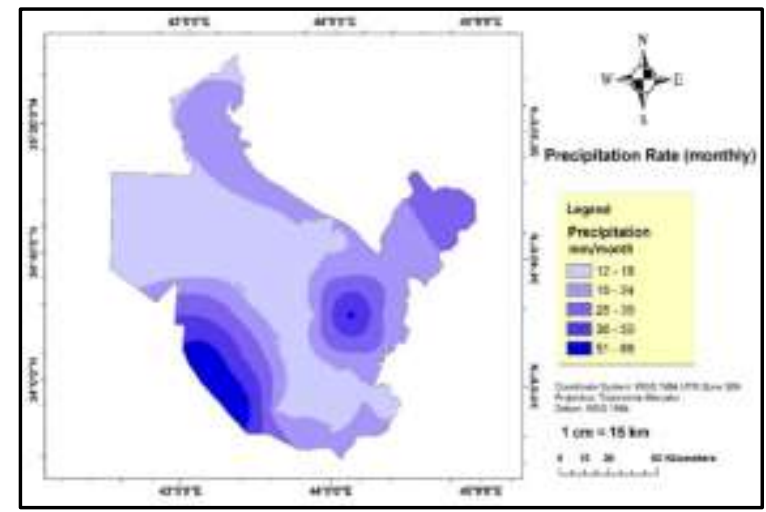

Figure 4: Monthly precipitation rate for the period $2000-2018$

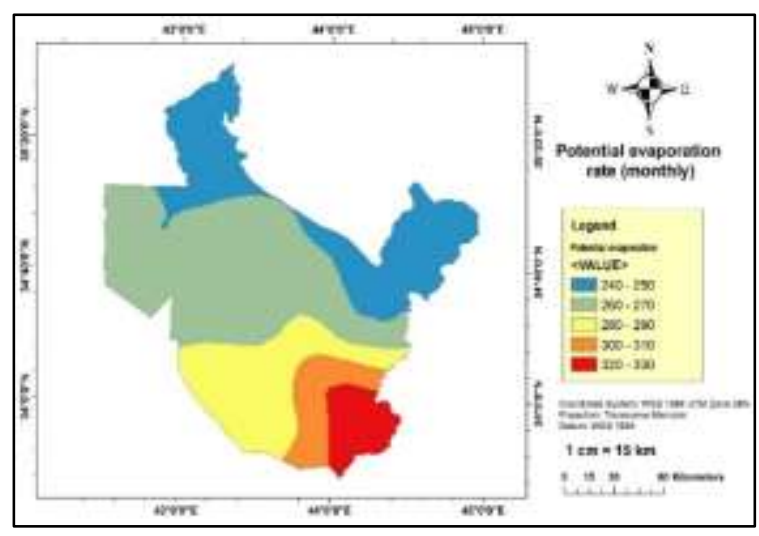

Figure 5: Monthly potential evaporation rate for the period 2000- 2018

c. Land cover data

Sentinel-2 Level-1C processing includes radiometric and geometric corrections with subpixel accuracy. The Level-1C product results from utilizing a digital elevation model in order to project the image in cartographic geometry. Per-pixel radiometric measurements are provided in Top of Atmosphere reflectance along with the parameters to transform them into radiance. Six images were used to obtain the NDVI layer (Figure 6) using Equation [15]:

$(\mathrm{NDVI})=\frac{N I R-V I R}{N I R+V I R}$

The NDVI is determined using the visible wavelength (Red) and near-infrared wavelengths (NIR). Strong vegetation will absorb most of the visible wavelengths that it receives and will reflect back a large proportion of the nearinfrared light, while poor condition vegetation will reflect more visible wavelength light and less near-infra-red light. The NDVI ratio for Sentinel2 is outlined in Equation 2:

$(\mathrm{NDVI})=\frac{\text { Band } 8-\text { Band } 4}{\text { Band } 8+\text { band } 4}$

The distance to roads was determined using Euclidean Distance (Figure 7), which can be defined as the straight-line distance between two points on a plane. It generates a raster from a vector layer that indicates the existing distances from the figure to the rest of the field in a visual and colorful way. The output Euclidean distance raster contains the measured distance from each cell to the nearest source.

Soil map was constructed from FAO (Figure 8), five classes of soil were found in the study area; which is young soils in alluvial deposits, soils with an accumulation of secondary calcium carbonates, soils with an accumulation of secondary gypsum, strongly saline soils, and sandy soils featuring (very weak or no soil development). 


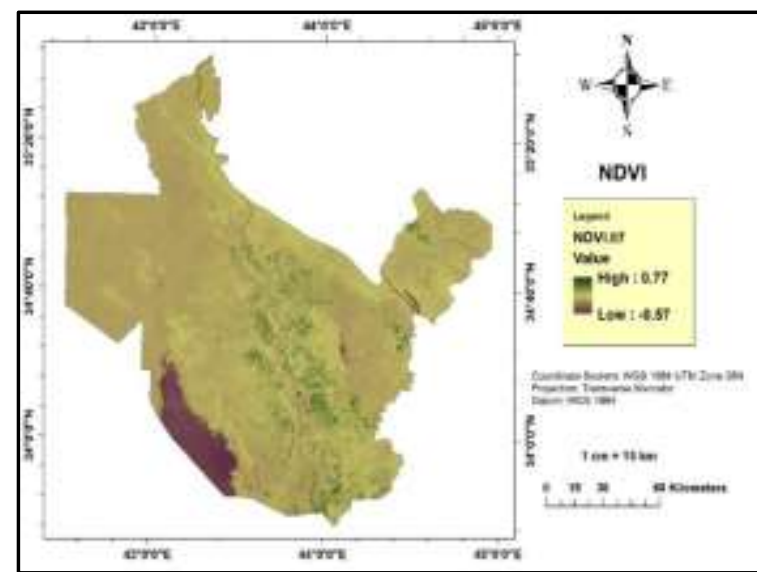

Figure 6: NDVI layer

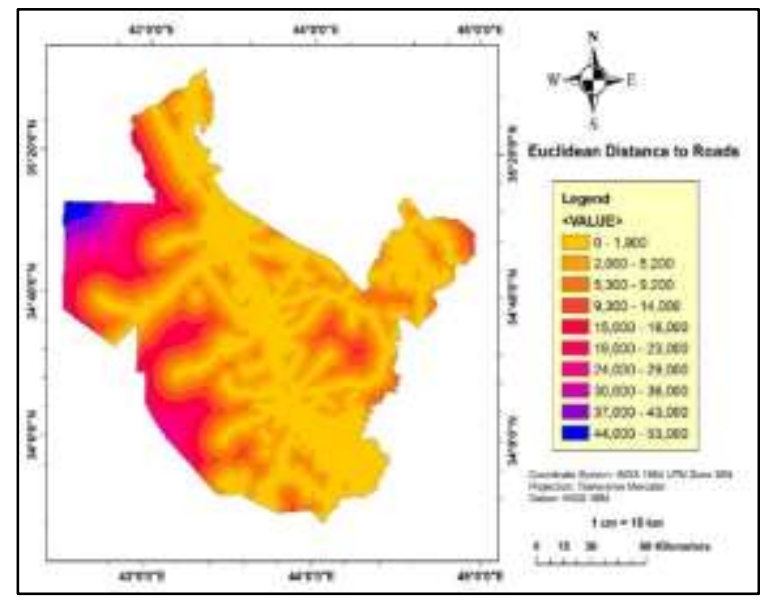

Figure 7: Euclidean distance to roads

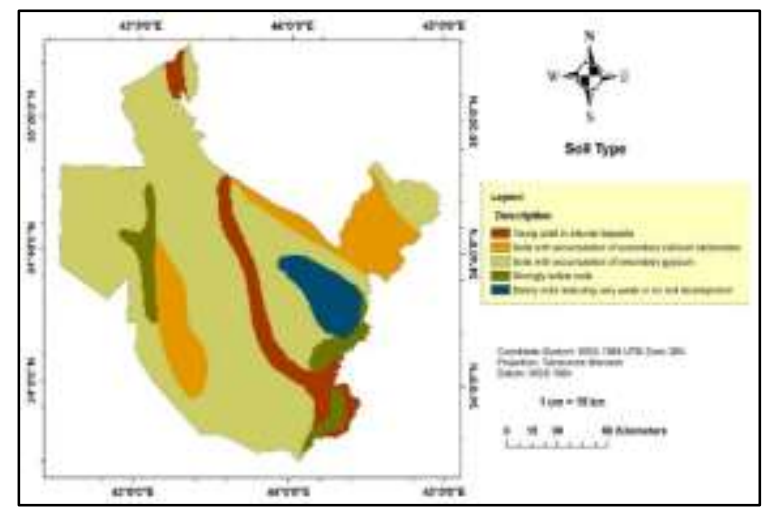

Figure 8: FAO soil map

\section{Multi-Criteria Evaluation}

Criteria evaluated as a fully continuous variable, Figure 9 shows the MCE steps. The criteria are called factors and reflect a different degree of suitability for the decision under consideration. The standardization process is converting the data to a uniform numerical scale [16]. In this study, MCE to identify the potential water-harvesting site was performed based on a number of criteria and constraints where seven specific criteria were chosen which is slope, roads, NDVI, stream order, precipitation, evaporation, and soil. After that, the Fuzzy Gamma overlay method was applied to create the final suitability map.

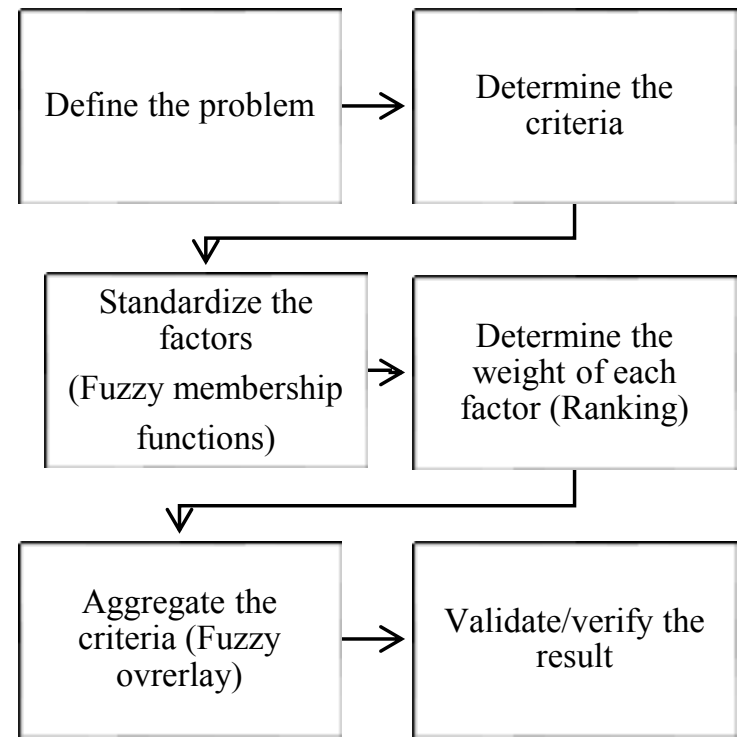

Figure 9: Multi-Criteria Evaluation (MCE) steps

\section{Fuzzy Logic Method}

The Fuzzy Logic method proposed by Zadeh in 1965 [17] is generally used to solve the complex topics and the membership function is employed to indicate the degree of the membership regarding a number of characteristics. Fuzzy logic membership enables the operator to decide that a site is suitable or unsuitable. The basic conception of the Fuzzy membership is replaced all layers value using range from 0 and 1 , where 0 means false while 1 means true and all values between 0 and 1 have represented a transition between 1 to 0 as shown in the equation below [18]:

$\mu(X)=0$ if $x<\min$

$\mu(x)=1$ if $x>\max$

other wise $\mu(x)=\frac{(x-\min )}{(\max -\min )}$

In this study, Fuzzy membership functions in Arc GIS 10.5 were applied to standardization the layers. The Fuzzy linear membership (FLM) applies a linear function between the minimum and maximum values specified by the user; any value below the minimum would be assigned a zero. The linear increasing or decreasing membership between two inputs was linearized in sigmoid shape.

\section{Fuzzy Logic Overlay}

The Fuzzy overlay is the final step in applying the Fuzzy logic to the criteria layers. In order to perform the Fuzzy overlay, one of the Fuzzy overlay types must be selected. There are five types of Fuzzy operators, which is, the Fuzzy OR, the Fuzzy AND, Fuzzy algebraic product, Fuzzy algebraic sum, and Fuzzy gamma operator. The 
methodology flowchart utilizing Fuzzy logic overlay was illustrated in Figure 10. In this study, the Fuzzy gamma operators were used which based on Fuzzy algebraic product and Fuzzy algebraic Sum, the equations were illustrated as follows [19]. The Fuzzy algebraic product is defined as:

$\mu$ combination $=\prod_{i=1}^{n} \mu_{i}$

Where $\mu_{\mathrm{i}}$ is the Fuzzy membership function for the layer, I, and $\mathrm{I}=1,2,3, \mathrm{n}$ layers are to be combined. The Fuzzy algebraic sum is defined as: $\mu$ combination $=\prod_{i=1}^{n}\left(\mu_{i}-1\right)$

In this, the operator output value is always larger than or equal to the largest contributing Fuzzy membership value. The gamma operation is defined as:

$\mu$ combination $=(\text { Fuzzy algebraic Sum })^{\lambda} \times$

(Fuzzy algebraic product) $^{(1-\lambda)}$

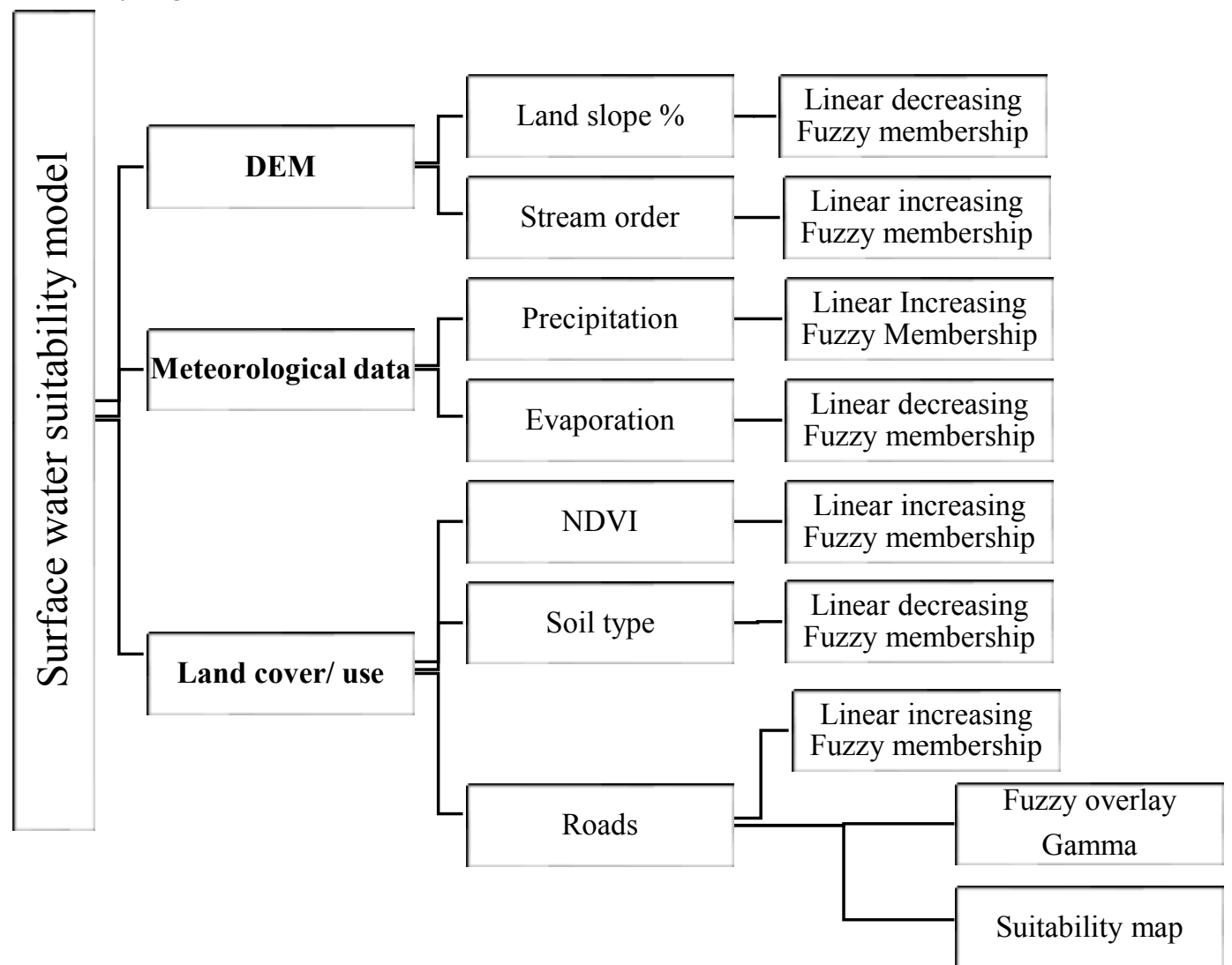

Figure 10: Surface water model utilizing Fuzzy logic overlay

\section{Criteria Identification}

Generally, in Iraq, there is no criteria standard for water-harvesting because the use of MCE is a new approach there so that all the criteria were evaluated according to other water harvesting

Table 1: Standardization layers used in surface water Fuzzy model

\begin{tabular}{|c|c|c|c|c|c|}
\hline No. & Thematic Layer & Type & $\begin{array}{l}\text { Source } \\
\end{array}$ & $\overline{C \text { Criteria }}$ & Linear Membership \\
\hline 1 & $\begin{array}{l}\text { Land slope } \\
\text { (Percentage) }\end{array}$ & Raster & STRM V.3 DEM Data & $\leq 8 \%$ & $\begin{array}{l}\operatorname{Min}=8 \% \\
\operatorname{Max}=0 \%\end{array}$ \\
\hline 2 & Stream order & Raster & STRM V.3 DEM Data & $>$ 3rd Order & $\begin{array}{l}\operatorname{Min}=3^{\text {rd }} \\
\operatorname{Max}=7^{\text {th }}\end{array}$ \\
\hline 3 & Precipitation & Vector & Satellite-based Data /TRMM & Maximize & $\begin{array}{l}\operatorname{Min}=12 \\
\operatorname{Max}=66\end{array}$ \\
\hline 4 & Evaporation & Vector & Satellite-based Data /GLDAS & Minimize & $\begin{array}{l}\operatorname{Min}=330 \\
\operatorname{Max}=240\end{array}$ \\
\hline 5 & NDVI & Raster & multispectral satellite image & $>0$ & $\begin{array}{l}\operatorname{Min}=0 \\
\operatorname{Max}=0.77\end{array}$ \\
\hline 6 & Soil type & Vector & FAO maps & Minimize & $\begin{array}{l}\operatorname{Min}=3 \\
\operatorname{Max}=1\end{array}$ \\
\hline 7 & Roads & Vector & Land use shapefile & $>100 \mathrm{~m}$ & $\begin{array}{l}\operatorname{Min}=100 \\
\operatorname{Max}=53000\end{array}$ \\
\hline
\end{tabular}

studies of such as AL-Adamat, 2008 [20], FAO, 1999 [21], and Victor, 2016 [22]. The criteria that were used in the study are illustrated in Table 1. 


\section{Results and Discussion}

\section{Standardization}

In order to apply the Fuzzy overlay, all the criteria layers should be on a uniform scale on the same units and therefore needed to be standardized [23]. In addition, the vector-layers must convert to raster format to aggregate these layers. Figure 11 shows layers standardizations using Fuzzy linear membership (FLM).

a. Slope

The slope is the inclination or gradient of a surface and generally expressed as a percent. Because of its influence on runoff and drainage, the slope is important for soil formation and management. According to FAO standard guidelines, the slopes that are less than $2 \%$ are very suitable for surface irrigation. Conversely, the slopes that are greater than $8 \%$ are not commonly recommended [21]. The slope layer was generated from STRM V. 3 DEM data. The slope values vary between $0-100$. According to the FAO standard, the criteria of the slope must be less than $8 \%$. The decreasing linear Fuzzy membership was applied to standardize the slope layer, the maximum slope was set as zero and the minimum slope was $8 \%$.

b. Stream Order

The stream order layer was generated from STRM V.3 DEM data using the Strahler method [24]. The Fuzzy linear increasing membership was used to standardize the stream order layer. The stream order value varies from one to seven, and the criteria of stream orders were higher than third order.

\section{c. Precipitation}

Time-averaged map of precipitation rate monthly was driven from TRMM data. The data interpolated using the Ordinary Kriging method. The monthly precipitation rate varies between 12$55 \mathrm{~mm} / \mathrm{month}$. The Fuzzy linear increasing membership was used to standardize the precipitation layer.

\section{d. Evaporation}

The potential evaporation rate monthly was downloaded from GLDAS Model for the period 2000-Jan - 2018-Jan. The monthly potential evaporation varies between $240-330 \mathrm{~W} / \mathrm{m}^{2}$. The Fuzzy linear decreasing membership was used to standardize the evaporation layer.

\section{e. NDVI}

NDVI layer was obtained from analyses the Sentinel 2 images. The NDVI value varies from -0.57 to 0.77 . The increasing Fuzzy linear membership was used to standardize the NDVI and the criteria of NDVI was greater than zero.

f. Soil

The soil map was obtained from FAO soil maps as a vector format. This feature was converted to a raster. The decreasing Fuzzy linear membership was used to standardize the soil layer.

g. Roads

Roads distance layer value varies from 0 to 53000 $\mathrm{m}$, the criteria of the road must be greater than $100 \mathrm{~m}$. The Fuzzy linear increasing membership was used to standardize the road layer, $100 \mathrm{~m}$ was set as the maximum distance and the minimum distance set as $53000 \mathrm{~m}$.

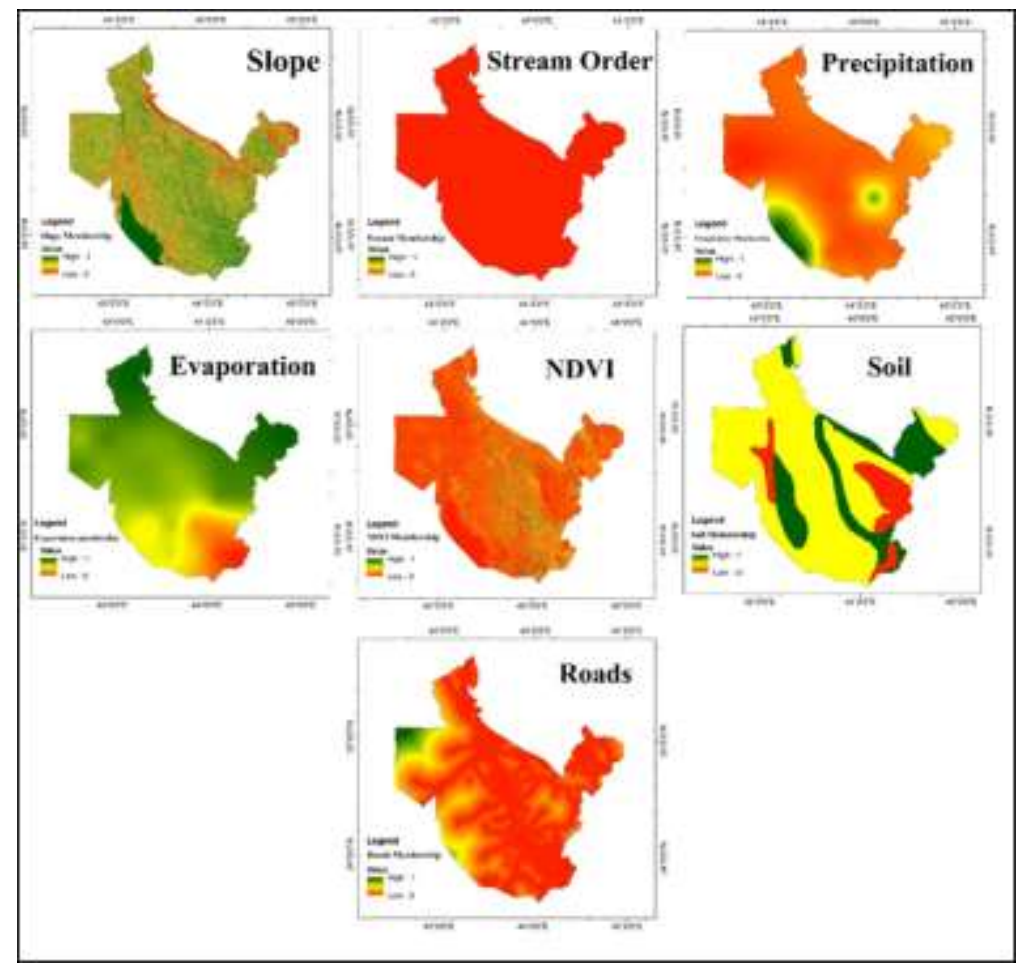

Figure 11: Criteria layers standardization using FLM 


\section{Sites Selection}

The slope, stream order, soil, roads, NDVI, evaporation, and precipitation were collective together after standardized using the Fuzzy overlay by Gamma 0.9 operation to identify the potential water harvesting sites in the study area. The resulting map shows a wide range (0 to 53\%) of the degree of suitability of water-harvesting sites within the study area (Figure 12).

To make the results logically and to limit the number of potential sites in the investigated area, this study adopted using $\geq 0.50$ value suitability which results in 12 potential sites that distributed within the study area (Figure 13); these sites were fallen on the stream order within the study area.

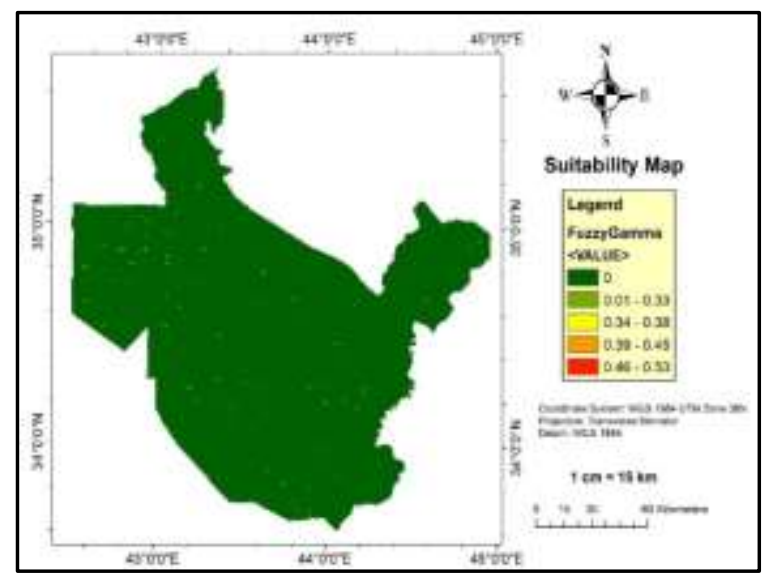

Figure 12: Final suitability map using Fuzzy overlay

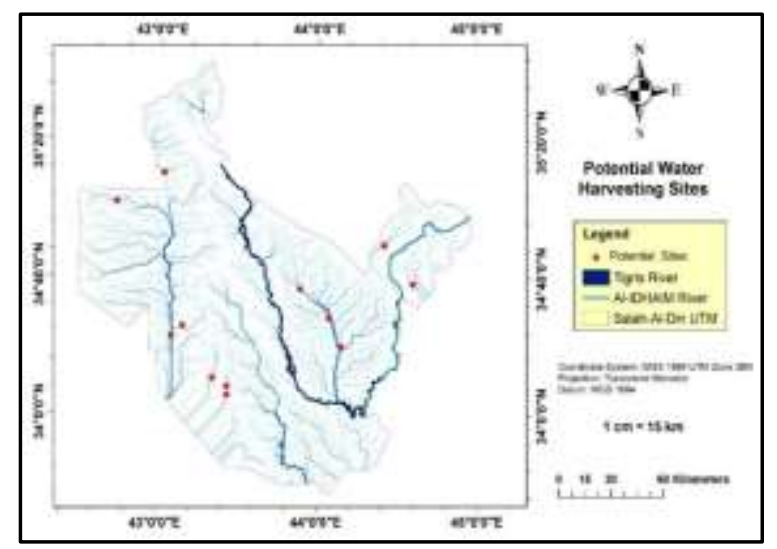

Figure 13: Potential water harvesting sites

\section{Conclusion}

- This study demonstrated the capabilities of GIS technology using Fuzzy logic models with remote sensing data, to identify the potential sites for harvesting water.

- GIS-based MCE were used to produce a suitability map for potential irrigation site. This was enabled through the application of various spatial analysis tools. The analysis was applied to seven layers: stream order, roads, slope, soil, precipitation, evaporation and NDVI.

- Twelve potential water-harvesting sites within the study area have been identified according to the specific criteria used for this purpose and have a high potential for water harvesting.

- The results illustrate how GIS can be used as a decision-making tool in the water resources management in a scientific approach, which makes the decision making easier and accurate. Information derived from this study can be used to inform government, investors and other stakeholders on best land use practices.

\section{References}

[1] F. Ziadat, A. Bruggeman, T. Oweis, N. Haddad, S. Mazahreh, W. Sartawi and M. Syuof, "A participatory GIS approach for assessing land suitability for rainwater harvesting in an arid rangeland environment, "Arid Land Research and Management, Vol. 26, No.4, pp. 297-311, 2012.

https://doi.org/10.1080/15324982.2012.709214

[2] J. Malczewski, "GIS-based multi-criteria decision analysis: A survey of the literature," International Journal of Geographical Information Science, Vol. 20, No. 7, pp. 703-726, 2006.

https://doi.org/10.1080/13658810600661508

[3] Y. Xu, J. Sun, J. Zhang, Y. Xu, M. Zhang, and X. Liao, "Combining AHP with GIS in synthetic evaluation of environmental suitability for living in China's 35 major cities," Int. J. Geogr. Inf. Sci., Vol. 26, No.9, pp. 1603-1623, 2012.

https://doi.org/10.1080/13658816.2011.642800

[4] J. Malczewski, "GIS-based land-use suitability analysis: a critical overview," Progress in Planning, Vol. 62, pp. 3-65, 2004.

https://doi.org/10.1016/j.progress.2003.09.002

[5] V. Srivastava, H. B. Srivastava and R. C. Lakhera, "Fuzzy gamma based geomatic modelling for landslide hazard susceptibility in a part of Tons river valley, northwest Himalaya, India," Geomatics, Natural Hazards and Risk, Vol. 1, No.3, pp. 225-242, 2010. http://dx.doi.org/10.1080/19475705.2010.490103.

[6] Y. Chen, S. Khan and Z. Paydar, "To retire or expand? A Fuzzy GIS-based spatial multi-criteria evaluation framework for irrigated agriculture," Irrig. and Drain., Vol. 59, pp. 174-188, 2010. https://doi.org/10.1002/ird.470.

[7] A. Rikalovic, I. Cosic and D. Lazarevic, "GIS Based Multi-Criteria Analysis for Industrial Site Selection," Procedia Engineering, Vol. 69, pp. 10541063, 2014.

https://doi.org/10.1016/j.proeng.2014.03.090

[8] A. Adham, M. Riksen, M. Ouessar and C. Ritsema, "Identification of suitable sites for rainwater harvesting structures in arid and semi-arid regions: A review," International Soil and Water Conservation Research, Vol. 4, pp.108-120, 2016. 
https://doi.org/10.1016/j.iswcr.2016.03.001

[9] N.A. Aziz, R.H Hasan, and Z.T. Abdulrazzaq, "Optimum Site Selection for Groundwater wells using Integration between GIS and Hydrogeophysical Data," Engineering and Technology Journal, Vol. 36, Part A, No. 6, pp. 596-602, 2018.

http://dx.doi.org/10.30684/etj.36.6A.1

[10] H.H. Karim, T. Schanz and A.N. Ibrahim, "Integration between surface geoelectrical and geotechnical datasets in Salah Al-Din area, Central Iraq," $1^{\text {st }}$ International Conference for Geotechnical Engineering and Transportation ICGTE in 2415/4/2013, Eng. \& Tech. Journal, Vol.31, Part (A) No.20, 2013, pp. 237-261.

[11] S.Z. Jassim and J. Goff, "Geology of Iraq," Dolin, Prague and Moravian Museum, Brno, 341 P, 2006.

[12] NASA, "The Shuttle Radar Topography Mission (SRTM) Collection User Guide," 2015. https://pdaac.usgs.gov/sites/default/files/public/ measures/docs/NASA_SRTM_V3.pdf

[13] Z.T. Abdulrazzaq, N.A. Aziz and A.A. Mohammed, "Flood modelling using satellite-based precipitation estimates and digital elevation model in eastern Iraq," International Journal of Advanced Geosciences, Vol. 6, No. 1, pp.72-77, 2018.

https://doi.org/10.14419/ijag.v6i1.8946

[14] M.P.R. Rodell, U. Houser, J. Jambor, K. Gottschalck, C.-J. Mitchell, K. Meng, A. Arsenault, J. Cosgrove, M. Radakovich, J. K. Bosilovich, J. P. Entin, D. Walker, Lohmann and D. Toll, "The Global Land Data Assimilation System," Bull. Amer. Meteor. Soc., Vol. 85, No. 3, pp. 381-394, 2004.

https://doi.org/10.1175/BAMS-85-3-381

[15] T.N. Carlson and D.A. Ripley, "On the relation between NDVI, fractional vegetation cover, and leaf area index," Remote Sensing of the Environment, Vol. 62, No. 3, pp. 241-252, 1997.

https://doi.org/10.1016/S0034-4257(97)00104-1

[16] H. Voogd, "Multi-criteria evaluation for urban and regional planning," London, 1983.

[17] L.A. Zadeh, "Fuzzy sets," Information and control, Vol. 8, p. 338, 1965.

[18] U.C Benz, P. Hofmann, G. Willhauck, I. Lingenfelder, and M. Heynen, "Multi-resolution, object-oriented Fuzzy analysis of remote sensing data for GIS-ready information," ISPRS Journal of Photogrammetry and Remote Sensing, Vol. 58, No.34, pp.239-258, 2004.

[19] H. Shahabi M. Hashim, B.B. Ahmad "Remote sensing and GIS-based landslide susceptibility mapping using frequency ratio, logistic regression, and Fuzzy logic methods at the central Zab basin, Iran," Environmental Earth Sciences, Vol. 73, p. 8647, 2015. https://doi.org/10.1007/s12665-015-4028-0

[20] R. Al-Adamat, "GIS as a decision support system for siting water harvesting ponds in the basalt aquifer/NE Jordan," Journal of Environmental
Assessment Policy and Management, Vol. 10, No. 2, pp. 189-206, 2008.

https://doi.org/10.1142/S1464333208003020

[21] FAO "The future of our land facing the challenge," Guidelines for integrated planning for sustainable management of land resources. Rome, 1999.

[22] M.W. Victor, "GIS based Multi Criteria Analysis in Mapping Potential for Irrigated Agriculture. Case study: Machakos County," MSc thesis, University Of Nairobi, 2016.

[23] H.A. Effat and O.A. Hassan, "Designing and evaluation of three alternatives highway routes using the analytical hierarchy process and the least-cost path analysis, application in Sinai Peninsula, Egypt," Egypt. J. Remot. Sens. Space Sci., Vol.16, No. 2, pp. 141-151, 2013. https://doi.org/10.1016/j.ejrs.2013.08.001

[24] A.N. Strahler, "Hypsometric (area-altitude) analysis of erosional topology," Geological Society of America Bulletin, Vol. 63, No. 11, pp. 1117-1142, 1952.https://doi.org/10.1130/00167606(1952)63[1117:HAAOET]2.0.CO;2 